\title{
Sustainable Growth Rate Repealed, MACRA Revealed: Historical Context and Analysis of Recent Changes in Medicare Physician Payment Methodologies
}

\author{
(D).A. Hirsch, DH.B. Harvey, (D) R.M. Barr, (D)W.D. Donovan, (D) R. DuszakJr, (D) G.N. Nicola, (DP.W. Schaefer, and (D). Manchikanti
}

ABBREVIATIONS: APM = Alternative Payment Models; CHIP = Children's Health Insurance Program; CMS = Centers for Medicare and Medicaid Services; MACRA = Medicare Access and CHIP Reauthorization Act of 2015; MIPS = Merit-Based Incentive Payment System; SGR = Sustainable Growth Rate

$\mathbf{I}_{\mathrm{s}, \mathrm{m}}^{\mathrm{m}}$ ntended to provide long-term control of Medicare physician spending, the Sustainable Growth Rate (SGR) tied certain Medicare Part B payments to the economic performance of the United States. Although sensible in concept, the political implementation of the SGR resulted in a failed and perilous policy that challenged sensibilities and practice since its implementation in 1997. Few professions or businesses could function with the potential for an overnight diminution in compensation of doubledigit percentages, yet physicians have survived under this methodology for almost 2 decades. Given the payment structure of imaging centers, many radiology practices have been particularly vulnerable. The Medicare Access and CHIP Reauthorization Act of 2015 (MACRA) eliminated this sword of Damocles of the SGR once and for all. ${ }^{1}$ However, by mandating the Merit-Based Incentive Payment System (MIPS) and Alternative Payment Models (APM), MACRA creates both challenges and opportunities for radiologists - and all other Medicare-participating health care professionals. For instance, by 2022, certain providers could experience adjustments in certain Medicare Part B payments by as much as $\pm 9 \%$ based on performance metrics collected in 2021: fluctuations comparable in magnitude to the envisioned SGR cuts. This Vignette describes the political and health care environment leading to the SGR repeal and describes, in detail, the new physician payment methodologies advanced under MACRA.

From the Department of Radiology (J.A.H., H.B.H., P.W.S.), Massachusetts General Hospital, Boston, Massachusetts; Harvard Medical School (J.A.H., H.B.H., P.W.S.), Boston, Massachusetts; Mecklenburg Radiology Associates P.A. (R.M.B.), Charlotte, North Carolina; Norwich Diagnostic Imaging Associates (W.D.D.), Norwich, Connecticut; Department of Radiology and Imaging Sciences (R.D.), Emory University, Atlanta, Georgia; Harvey L. Neiman Health Policy Institute (R.D.), Reston, Virginia; Hackensack University Medical Center (G.N.N.), Hackensack, New Jersey; Pain Management Center of Paducah (L.M.), Paducah, Kentucky; and Department of Anesthesiology and Perioperative Medicine (L.M.), University of Louisville, Louisville, Kentucky.

Please address correspondence to H. Benjamin Harvey, MD, JD, Department of Radiology, Massachusetts General Hospital, 175 Cambridge St, Suite 200, Boston, MA 02114; e-mail: hbharvey@partners.org

http://dx.doi.org/10.3174/ajnr.A4522

\section{INTRODUCTION AND FOCUSED HISTORY}

In 1997, the federal government enacted what, in retrospect, seems to have been a confusing policy: to assist balancing the federal budget by curtailing growth in professional-side medical spending. The Balanced Budget Act of 1997 introduced the SGR into Medicare payment policy. ${ }^{2}$ The SGR concept is not novel to the medical profession: It was derived from the business world, where it describes best-case-scenario growth. For example, an SGR may be used to define an expansion strategy for a given line of business based on preconceived plans, definitions, and limitations.

Parts B and D of the Medicare program are financed from the Supplementary Medical Insurance Trust Fund. The Supplementary Medical Insurance is financed through fees paid by beneficiaries and federal dollars derived from taxation. Part B provides professional-component reimbursement to physicians and allied health professionals and the global fees to free-standing imaging centers. (Payment of the technical component of hospital-based imaging services is made through Medicare Part A and was not addressed by the SGR.)

Targets set by the SGR were not direct limits on expenditures. Instead, the Medicare Fee Schedule Update is adjusted to reflect the comparison of actual expenditures with target expenditures. Thus, if service expenditures exceed the SGR target, the Medicare fee schedule update is reduced to meet the deficit, and vice versa. The SGR target is calculated on the basis of projected changes in 4 factors: 1) fees for physicians' services, 2) the number of Medicare beneficiaries, 3) US gross domestic product, and 4) service expenditures based on changing law or regulations. ${ }^{3}$ Simply stated, the SGR formula tied growth in physician spending to the economic performance of the United States, theoretically preventing growth in Medicare physician spending from exceeding the annual growth in gross domestic product. ${ }^{4}$ The Centers for Medicare and Medicaid Services (CMS) used money spent between April 1, 1996, and March 31, 1997 ( $\$ 48.9$ billion dollars) as the basis for its calculation of future program goals.

Since the 1970s, growth of health care expenditures has typi- 
cally outstripped rates of gross domestic product growth in the United States. ${ }^{5}$ This difference naturally raises questions about the wisdom of linking professional-side physician reimbursement to gross domestic product. The early years of the SGR included a period in which the federal budget was, in fact, balanced, and the formula-based correction did not result in lower physician reimbursement rates. However, this changed in 2001 and subsequent years when the SGR methodology indicated that health care spending was above its target, which meant that Part B payments needed to be cut to stay within the legislated goal. ${ }^{6,7}$

\section{ORGANIZED MEDICINE SPRINGS INTO ACTION}

At its height, the SGR methodology called for an overnight reduction in Part B payments of over 25\%. The medical community vociferously argued that such reimbursement cuts constituted a direct threat to patient care by making resource planning impossible, among other challenges. Innumerable medical professional societies-including but not limited to the American Medical Association, the American College of Radiology, the American Society of Neuroradiology, the American Society of Interventional Pain Physicians, and the Society of NeuroInterventional Surgery-issued formal opinions or published articles calling for the elimination of the SGR. ${ }^{8}$ The Medicare Payment Advisory Commission also threw its support behind SGR reform. ${ }^{9}$

Understanding the disruption that SGR-mandated cuts would mean for federally supported patient care, Congress perennially blocked the implementation of the cuts through last-minute legislative actions, while repeatedly declining to enact permanent reform. By 2010, the cumulative cost of these Congressional fixes was estimated to be nearly $\$ 300$ billion dollars. ${ }^{10}$

\section{THE TIDE TURNS}

Health care reform was the pre-eminent domestic policy issue in the first term of the Obama presidency, resulting in the Affordable Care Act of 2010. ${ }^{11}$ Interestingly, the Affordable Care Act did not explicitly address the SGR, despite the potential of the SGR to dramatically affect health care services in the United States. ${ }^{12}$ Around the time of the Affordable Care Act, many policy experts were discussing a potential 10-year freeze in physician payments, as a longer term workaround to the SGR; outright repeal of the SGR was still deemed too difficult. However, in 2013, an opportunity for action was facilitated by publication of a Congressional Budget Office report, which cut the cost estimates for an SGR solution by nearly half compared with prior years, namely due to the recession and slow subsequent economic growth. ${ }^{13}$ This report resulted in a fresh set of ideas and rejuvenated interest in permanently repealing the SGR. Several proposals were generated, but Congress was unable to unite behind a single bill. ${ }^{14}$

In a move that took many in the health policy and physician communities by surprise, an SGR repeal bill was introduced in Congress and was speedily passed by both houses earlier this year. On March 26, 2015, the House overwhelmingly, by a vote of 392 to 37, passed House Resolution 2: the Medicare Access and CHIP Reauthorization Act of 2015. On April 14, 2015, the Senate ratified MACRA by a similar overwhelming vote of 92 to 8 . Two days later on April 16, President Obama signed MACRA into law. ${ }^{1}$ MACRA represents a crescendo of bipartisan health care reform efforts during the past decade, including the Physician Quality Reporting System, Physician Quality Reporting Initiative, and Medicare Advantage.

Among its many aims, MACRA was intended to improve the milieu of physician reimbursement by encouraging payments based on quality rather than volume. ${ }^{15}$ Supported by pundits and the broader medical community, the President hailed the new Medicare package as a "significant bipartisan achievement." However, beyond just further codifying "value-based payment models," MACRA repealed the SGR, thereby eliminating the association between Part B payments and the gross domestic product. ${ }^{1}$ As such, MACRA did away with the $21.2 \%$ correction to physician payments that was scheduled to go into effect in 2015. Instead, MACRA provides annual 0.5\% reimbursement increases from July 2015 through 2019; then from 2020 through 2025, physician reimbursement will be held steady; and finally in 2026 and beyond, the law provides for 2 separate update paths based on the physician payment methodology selected by the provider (described in detail below). However, the current schedule of increases and freezes could be altered in any subsequent Congress.

\section{NO MORE SGR, BUT IS MACRA JUMPING FROM THE FRYING PAN INTO THE FIRE?}

In January 2015, the Secretary of the Department of Health and Human Services, Sylvia Burwell, presented her vision for the future of health care delivery and Medicare payment policy in a comment in the New England Journal of Medicine. ${ }^{16}$ Burwell described several goals for transforming the volume-based, fee-forservice system predominating US health care into one that is value-based. ${ }^{17}$ However, a clear strategy for reaching those goals was not explicitly described. Enter MACRA.

MACRA provides the bridge from ethereal ideas of valuebased payment to on-the-ground implementation. By providing a detailed strategy for enacting value-based payments, MACRA has taken the Burwell doctrine from proselytization into practice. The 2 major value-based physician payment methodologies laid out in MACRA are the Merit-Based Incentive Payment System and Alternative Payment Models. The former, MIPS, represents "valuebased light" and essentially continues traditional fee-for-service but imbues it with new value-based performance requirements. APMs are risk-sharing, value-based payment schema and represent a more complete departure from traditional fee-for-service. These 2 physician payment methodologies are described in detail in dedicated sections below.

\section{RELATIVITY IN A VALUE-BASED PARADIGM}

Before MACRA, it was uncertain how historical concepts of relativity and actual reimbursement would play into value-based paradigms of the future. In the pre-MACRA fee-for-service system, determining values for physician reimbursement relied on a complex interplay between several committees of the American Medical Association and CMS. The Current Procedural Terminology Committee establishes the codes that are then used to characterize procedures. ${ }^{18}$ On a code-by-code basis, the Relative Value Scale Update Committee values physicians' work to establish relative values across specialty lines. ${ }^{19}$ The American Society of Neuroradiology is very active in this process, with formal representation 
on both the Current Procedural Terminology Committee and the Relative Value Scale Update Committee to foster fair valuation of neuroradiology services relative to services of other physician providers. $^{20,21}$ MACRA preserves elements of the relativity-based system by providing a methodology for relating fee-for-service to value-based payments. As such, the relative value unit system and the Relative Value Scale Update Committee are likely to continue to play central roles in determining physician payment reimbursement under MACRA payment schemes. This necessitates an enduring commitment to data-driven evidence to support Relative Value Scale Update Committee decisions and strong and effective neuroradiology representation on the Relative Value Scale Update Committee.

\section{MERIT-BASED INCENTIVE PAYMENT SYSTEM}

The Merit-Based Incentive Payment System will allow physicians to continue practicing in a fee-for-service environment, but new quality metrics must be reported to qualify for ongoing reimbursement. Recognizing that there is a complex first generation of quality metrics in existence (eg, Value-Based Payment Modifier program, Physician Quality Reporting System incentive), MACRA envisions a consolidation of the current quality metrics into a unified quality framework. As such, Congress charged CMS with the task of establishing a system that brings the current quality programs together into a comprehensive scheme that will assess the performance of health care professionals participating in Medicare. $^{1}$

To this end, MACRA introduces 4 performance categories. These performance categories repackage some of the existing quality metrics and introduce a new one. For instance, the MIPS simplifies the names of the Value-Based Modifier program and Physician Quality Reporting System Incentive/Disincentive Program to "Resource Use" and "Quality," respectively, representing 2 of the performance categories. The third performance category, "Clinical Practice Improvement Activities," is new and will focus on improvement in the domains of patient access (particularly for urgent care), population health management and care coordination, beneficiary engagement, patient safety, and practice assessment. The Meaningful Use Incentive Program for Electronic Health Records, the fourth performance category, remains largely unchanged under MIPS.

MACRA attempts to reduce the hassle and administrative challenge of demonstrating compliance by uniting these 4 performance categories via the use of Qualified Clinical Data Registries. Qualified Clinical Data Registries are CMS-approved entities that can satisfy each of the 4 performance categories created by MIPS. The good news for the radiology community is that the National Radiology Data Registry, created and maintained by the American College of Radiology, is now CMS-approved as a Qualified Clinical Data Registry. ${ }^{22}$ The National Radiology Data Registry currently supports 14 Physician Quality Reporting System measures, allowing eligible providers to reach the requirement of at least 9 Physician Quality Reporting System measures across 3 National Quality Strategy domains. ${ }^{22}$

Starting in 2019, eligible health care providers participating in MIPS will receive a composite numeric score for their performance relating to the 4 value-based categories described above. The score will range from 0 to 100 . Using a set threshold, the
Secretary of Health and Human Services will compare the provider's performance score with the performance of the broader community. Although not yet set in stone, it is envisioned that the performance threshold for each year will likely be the median or mean of the performance scores of all MIPS-eligible professionals from a prior time period as determined by the Secretary. Only those providers continuing to participate in fee-for-service Medicare will be eligible for MIPS, whereas providers participating in an Alternative Payment Model are governed by a different reimbursement framework described in detail below.

Under MIPS, payment adjustments (up or down) will be tied to how the eligible provider performs on his or her performance measures. If one exceeds the threshold, starting in 2019, a bonus ("positive adjustment") will be applied. The better one does, the larger the adjustment, within the limits of budget neutrality. The policy even allows super bonuses for those with exceptional performance, with aggregate additional payments of up to $\$ 500$ million dollars annually from 2019 to $2024 .{ }^{1}$ For those providers who have performance measures at the threshold, no adjustment will be made. Last, for those that do not achieve the performance threshold, a penalty ("negative adjustment") will be enacted. The MIPS positive or negative adjustment factor will be $4 \%$ in 2019, $5 \%$ in 2020, 7\% in 2021, and 9\% in 2022 and thereafter. ${ }^{1}$ This methodology essentially results in a shifting of payments from underperformers to performers. At its peak, MIPS could result in payment fluctuations comparable in magnitude with those envisioned at the height of the SGR. The effectiveness of this incentive structure on improving health care quality and the potential negative impact of said adjustments on practice finances remain unclear and are largely untested on this scale.

\section{ALTERNATIVE PAYMENT MODELS}

Under MACRA, the second new pathway for physician payment from Medicare is through participation in an Alternative Payment Model. APMs target volume-based incentives and have grown from nonexistent entities to prevalent health care payment models within the past 5 years. Multiple approaches are currently being assessed in trials. ${ }^{23,24}$

By November 2016, the Health and Human Services Secretary is required to establish specific criteria for physician-focused APMs, including models for specialist physicians. Stakeholders are being given the opportunity to submit proposals for such payment models, and these will be reviewed by a new PhysicianFocused Payment Model Technical Advisory Committee. This advisory committee will report directly to the Secretary of Health and Human Services for policy-making decisions that relate to reimbursement.

Of particular note to radiologists, MACRA provides different ways to achieve APM status. The first approach requires that a substantial portion of a physician's or group's Medicare revenue come through an APM. A second approach would recognize APM revenue from both Medicare and other payers. This recognition would allow eligible professionals to qualify for bonuses even if APM options in their area are limited. One could envision this applying to radiologists because traditional participation in accountable care organizations can be challenging for certain types of specialists. ${ }^{25}$ 
In 2019-2020, at least 25\% of Part B services must be provided by an eligible APM entity, such as a Medicare Shared Savings Program for Accountable Care Organizations or similar programs created by the Centers for Medicare and Medicaid Innovation. In 2021-2022, this escalates to 50\% of Part B services being provided by an eligible APM entity or via another approved riskbased, quality-measured arrangement. Finally, in 2023 and thereafter, $75 \%$ percent of Part B services must meet this criterion. If this rapid, and arguably hasty, pace can be achieved, the inertiaridden US health care system will have been transitioned from volume-based to value-based care in less than a decade's time. ${ }^{25}$

MACRA encourages providers to choose the APM physician payment model over the MIPS model by giving APM participants more favorable reimbursement. If providers participate in a qualifying APM, they will receive a bonus each year from 2019 through 2024 equal to $5 \%$ of the estimated aggregate payment amounts for covered Part B professional services for the preceding year. Starting in 2026, APM participants will benefit from a more favorable annual conversion factor update of $0.75 \%$ compared with $0.25 \%$ for participants in the MIPS program.

\section{SELECTED ADDITIONAL ELEMENTS OF MACRA}

Several other areas are of interest to radiologists and neuroradiologists in MACRA. One example is the mandate to have interoperable, certified electronic health records by the start of 2019. Radiologists are keenly aware of the difficulties of getting electronic health record systems to interact with each other in a functional manner. However, it seems likely that the exchange of electronic health records might include digital images. For this reason, radiologists should anticipate the implications for their practices going forward.

CMS has recently begun releasing provider payment information to the public. The information released to date has been spotty and poorly contextualized, and the lay media has been left to explore the findings. ${ }^{26}$ As part of MACRA, CMS will expand the information released to the public domain.

The reauthorization of the Children's Health Insurance Program (CHIP) is another important achievement of MACRA. CHIP assists millions of children and pregnant women who do not qualify for Medicaid because their income is too high. MACRA extends funding for this program through fiscal year 2017.

\section{HOW WILL MACRA BE FINANCED?}

Above, we described how previous effort in Congress to permanently repeal the SGR fell short because there was no accepted mechanism to pay for the cost of doing so. How was that solved with this legislation? In reality, it was not. First, Medicare is going to expand what is generally known as means testing. As such, MACRA decreases the thresholds at which high-income beneficiaries pay higher Medicare premiums. Second, Medicare reimbursements for post-acute care facilities such as inpatient rehabilitation and skilled nursing facilities will be limited to a $1 \%$ increase in 2018. Furthermore, MACRA replaces an expected one-time payment increase of $3.2 \%$ to inpatient hospital payment rates in 2018, with 0.5\% increases from 2018 through 2023. As a result, MACRA fundamentally shifts money previously earmarked for hospitals and other facilities to physicians. Taken together, these offsets will only cover a portion of the cost of the legislation.

\section{TAKE-HOME POINTS}

- The Sustainable Growth Rate was a sensible attempt to limit historically rapid growth in physician spending to the economic performance of the United States; but the political implementation resulted in a failed and perilous policy.

- The Medicare Access and CHIP Reauthorization Act of 2015 eliminated the SGR and, in doing so, removed the perennial threat of $20 \%$ cuts in physician payments, which would have threatened patient access to health care services.

- By defining 2 new Medicare physician payment methodologies, the Merit-Based Incentive Payment System and the Alternative Payment Models, MACRA charts a path away from fee-forservice payments and toward value-based payments. Congress has mandated a rapid, and arguably hasty, transition to valuebased payments models, with widespread adoption of these new payment models required as early as 2019. By understanding the risks and opportunities under these varying payment models, radiologists can proactively seek the value-based physician payment methodology that best meets their needs or can even craft specialty-specific APMs themselves.

Disclosures: Joshua A. Hirsch—UNRELATED: Consultancy: Medtronic, CareFusion, Comments: Medtronic, Interventional Spine, ongoing; CareFusion, single non-Continuing Medical Education event in past 12 or 36 months; Stock/Stock Options: Intratech (development-stage stroke company). Robert M. Barr-UNRELATED: Board Membership: I serve on the board of Novant Health and the Harvey L. Neiman Health Policy Institute. These are both unpaid positions; Payment for Lectures (including service on Speakers Bureaus): academic institutions only. Laxmaiah Manchikanti-UNRELATED: Semnur Pharmaceuticals, Comments: provided limited consulting services to Semnur Pharmaceuticals, which is developing nonparticulate steroids.

\section{REFERENCES}

1. Medicare Access and CHIP Reauthorization Act of 2015. (2015). 42 USC 1305.

2. Balanced Budget Act of 1997. (1997). 42 USC 4511, 4512.

3. Hirsch JA, Rosman DA, Liu RW, et al. Sustainable growth rate 2013: time for definitive intervention. J Neurointerv Surg 2013;5:382-86 CrossRef Medline

4. Thrall JH. Unintended consequences of health care legislation. JAm Coll Radiol 2011;8:687-91 CrossRef Medline

5. United States Department of Labor, Bureau of Labor Statistics. Spotlight on Statistics: Health Care. November 2009. http://www.bls.gov/ spotlight/2009/health_care/. Accessed June 7, 2015

6. Congressional Budget Office. Medicare's payments to physicians: the budgetary impact of alternative policies relative to CBO's March 2012 baseline. July 30, 2012. http://www.cbo.gov/sites/default/files/cbofiles/ attachments/43502-SGR\%20Options2012.pdf. Accessed June 7, 2015

7. Medicare Payment Advisory Commission. Report to the Congress: Medicare and the Health Care Delivery System. Review of CMS's preliminary estimate of the 2013 update for physician and other professional services. June 2012. http://www.medpac.gov/documents/reports/jun12_appa.pdf?sfvrsn=0. Accessed June 7, 2015

8. House Energy and Commerce Committee. Re: The need to move beyond the SGR. Statement of the American Medical Association before the House Energy and Commerce Committee Subcommittee on Health Presented by Cecil B. Wilson, MD, May 5, 2011. http:// www.medsocdel.org/Portals/1/Health\%20Care\%20Reform\%20Info/ Proposal\%20from\%20the\%20AMA.pdf. Accessed June 7, 2015

9. Medicare Payment Advisory Commission. Report to the Congress. Medicare and the Health Care Delivery System. June 2012. 
http://www.medpac.gov/documents/reports/jun12_entirereport.pdf? sfvrsn $=0$. Accessed June 7, 2015

10. Fiegl C. Medicare SGR repeal price tag plummets. American Medical News. February 25, 2013. http://www.amednews.com/article/ 20130218/government/130219946/1/. Accessed June 7, 2015

11. Patient Protection and Affordable Care Act. (2010). 42 USC 18001.

12. Manchikanti L, Hirsch JA. Patient Protection and Affordable Care Act of 2010: a primer for neurointerventionalists. J Neurointerv Surg 2012;4:141-46 CrossRef Medline

13. Congressional Budget Office. The budget and economic outlook; fiscal years 2013 to 2023. February 2013. www.cbo.gov/sites/default/ files/cbofiles/attachments/43907-BudgetOutlook.pdf. Accessed June 7, 2015

14. Hirsch JA, Manchikanti L. The sustainable growth rate: a 2014 update. J Neurointerv Surg 2014;6:411-12 CrossRef Medline

15. Manchikanti L, Staats PS, Boswell MV, et al. Analysis of the carrot and stick policy of repeal of the sustainable growth rate formula: the good, the bad, and the ugly. Pain Physician 2015;18:E273-92 Medline

16. Burwell SM. Setting value-based payment goals: HHS efforts to improve U.S. health care. $N$ Engl J Med 2015;372:897-99 CrossRef Medline

17. Hirsch JA, Leslie-Mazwi TM, Barr RM, et al. The Burwell roadmap. J Neurointerv Surg 2015 Mar 5. [Epub ahead of print] CrossRef Medline

18. Hirsch JA, Leslie-Mazwi TM, Nicola GN, et al. Current procedural terminology; a primer. J Neurointerv Surg 2015;7:309-12 CrossRef Medline

19. Hirsch JA, Silva E 3rd, Nicola GN, et al. The RUC: a primer for neurointerventionalists. J Neurointerv Surg 2014;6:61-64 CrossRef Medline

20. Hirsch JA, Donovan WD, Leslie-Mazwi TM, et al. Component cod- ing and the neurointerventionalist: a tale with an end. J Neurointerv Surg 2013;5:615-19 CrossRef Medline

21. Donovan WD, Leslie-Mazwi TM, Silva E 3rd, et al. Diagnostic carotid and cerebral angiography: a historical summary of the evolving changes in coding and reimbursement in a complex procedure family. J Neurointerv Surg 2014;6:712-17 CrossRef Medline

22. American College of Radiology. NRDR PQRS Qualified Clinical Data Registry. http://www.acr.org/Quality-Safety/National-RadiologyData-Registry/Qualified-Clinical-Data-Registry. Accessed June 7, 2015

23. Meehan TM, Harvey HB, Duszak R Jr, et al. Accountable Care Organizations: what they mean for the country and for neurointerventionalists. J Neurointerv Surg 2015 May 18. [Epub ahead of print] CrossRef Medline

24. Harvey HB, Gowda V, Gazelle GS, et al. The ephemeral accountable care organization: an unintended consequence of the Medicare shared savings program. J Am Coll Radiol 2014;11:121-24 CrossRef Medline

25. McCurdy DA, Carder-Thompson EB, Cody DA, et al. President Signs MACRA: Permanently Reforms Medicare Physician Reimbursement Framework, Includes Other Medicare Payment, Program Integrity, and Policy Provisions. Reed Smith Client Alerts. April 16, 2015. www.reedsmith.com/Congress-Approves-MACRAPermanently-Reforms-Medicare-Physician-Reimbursement-Frame work-Includes-Other-Medicare-Payment-Program-Integrity-andPolicy-Provisions-04-16-2015/. Accessed June 7, 2015

26. USA Today. First look at Medicare data in 35 years. http://www. usatoday.com/story/news/nation/2014/04/09/government-releasesmedicare-physician-payment/7462923/. Accessed June 7, 2015 